\title{
Corrosion Inhibition Properties of Norepinephrine Molecules on Mild Steel in Acidic Media
}

\author{
Ahmed Yahya Issa Rubaye*, Hassan Thamir Abdulsahib, Ali Abdulrazzaq Abdulwahid \\ Department of Chemistry, College of Science, University of Basrah, Basrah, Iraq \\ Email: ${ }^{*}$ issaay86@yahoo.co.uk
}

Received 5 August 2015; accepted 13 September 2015; published 16 September 2015

Copyright (C) 2015 by authors and Scientific Research Publishing Inc.

This work is licensed under the Creative Commons Attribution International License (CC BY).

http://creativecommons.org/licenses/by/4.0/

c) (i) Open Access

\begin{abstract}
Inhibition performance of norepinephrine was investigated as corrosion inhibitors by Gravimetric technique and carried out with mild steel samples in $1 \mathrm{M}$ hydrochloric acid solution at room temperature. Norepinephrine exhibited maximum efficiency of $79 \%$ at $500 \mathrm{mg} / \mathrm{L}$. The results of Gravimetric studies revealed that the investigated compound acted as good corrosion inhibitor and the inhibition efficiencies increased with increase in the concentrations of the inhibitor IC. The experimental data complied with the Langmuir adsorption isotherm. Thermodynamic parameters, such as $\Delta G^{\circ}, \Delta H^{\circ}$, and $\Delta S^{\circ}$, were calculated using adsorption equilibrium constant obtained from the Langmuir isotherm. Results suggested that the norepinephrine adsorption on mild steel surface was a spontaneous and exothermic process. Scanning electron microscopy was used to investigate the mild steel surface at the highest corrosion inhibition studied concentration.
\end{abstract}

\section{Keywords}

Corrosion Inhibition, Adsorption, Efficiency, Langmuir Isotherm, Thermodynamic Parameters, Scanning Electron Microscopy (SEM)

\section{Introduction}

The action of corrosion inhibitors is closely related to factors such as: the types of functional groups, the number and type of adsorption sites, the charge distribution in the molecules and the type of interaction between the inhibitors and the metal surface [1]. A large number of organic compounds have been investigated as corrosion inhibitors for different types of metals [2]-[4]. Corrosion problems arise as a result of the interaction between the

\footnotetext{
${ }^{*}$ Corresponding author.
}

How to cite this paper: Rubaye, A.Y.I., Abdulsahib, H.T. and Abdulwahid, A.A. (2015) Corrosion Inhibition Properties of Norepinephrine Molecules on Mild Steel in Acidic Media. Journal of Encapsulation and Adsorption Sciences, 5, 155-164. 
aqueous acid solutions and mild steel, especially during the pickling process in which the alloy is brought in contact with highly concentrated acids. This process if not combated can lead to economic losses due to the corrosion of the alloy [5]. The use of inhibitors is one of the best options of protecting metals against corrosion. Several inhibitors in use are either synthesized from cheap raw material or chosen from compounds having heteroatoms in their aromatic or long-chain carbon system. The use of organic molecules as corrosion inhibitor is one of the most practical methods for protecting metals against the corrosion and it is becoming increasingly popular. The existing data show that organic inhibitors act by the adsorption and protect the metal by film formation.

Most of the effective inhibitors contain heteroatoms such as $\mathrm{O}, \mathrm{N}$, and $\mathrm{S}$ and multiple bonds in their molecules through which they are adsorbed on the metal surface [6]-[15]. It has been observed that adsorption depends mainly on certain physicochemical properties of the inhibitor group, such as functional groups, electron density at the donor atom, p-orbital character, and the electronic structure of the molecule [16]-[20]. The efficiency of an organic compound as an inhibitor is mainly dependent on its ability to get adsorbed on the metal surface which consists of a replacement of water molecules at a corroding interface.

However, most of these inhibitors are toxic to the environment. This has prompted the search for green corrosion inhibitors [21]. Acids and bases were utilized widely in industry for acid cleaning [22]. Mild steel is generally utilized as a part of different industries. Inhibitors are utilized as a part of industry to reduce the corrosion rate of diverse metals and amalgams which are in contact with forceful situations [23]. Previously the utilization of pickling inhibitors in descaling ways in the industry after hot moving utilizing inorganic acids has turned out to be compelling. Various organic compounds are utilized as consumption inhibitors for steel in acidic environments [24] [25]. Such compounds ordinarily contain hetroatoms and conjugated pi-systems [26] [27]. Numerous organic inhibitors adsorbed on the surface of the mild steel [28]. A coordinate covalent bond involving transfer of electrons from inhibitor to the metal surface may be formed. The strength of the chemisorptions bond depends upon the electron density on the donor atom of the functional group and also the polarizability of the group. When an $\mathrm{H}$ atom attached to the $\mathrm{C}$ in the ring is replaced by a substituent group (-NH, -NO, -CHO, or - $\mathrm{COOH}$ ), it improves inhibition [29]. The aim of this work is to study, using norepinephrine (Figure 1) and weight-loss measurements, on the corrosion inhibition of carbon steel in $1.0 \mathrm{M} \mathrm{HCl}$ solution.

Weight loss and scanning electron microscopy (SEM) techniques prove that the investigated inhibitor could be an effective corrosion inhibitor and its molecules adsorbed on the surface of mild steel. The output of this study is intended to be a cheap and an eco-friendly that can be used as a corrosion inhibitor for metals and alloys. No studies have been reported on the norepinephrine, as corrosion inhibitor, in terms of studying the gravimetric effect on the corrosion inhibition of carbon steel in $1.0 \mathrm{M} \mathrm{HCl}$ solution.

\section{Experimental}

\subsection{Chemicals}

All chemicals were used as received and were purchase from Sigma-Aldrich. Norepinephrine were purchase from local company in Baghdad-Iraq. Mild steel specimens were squeeze cut to form various specimens, with dimensions $1 \mathrm{~cm} \times 2 \mathrm{~cm} \times 0.05 \mathrm{~cm}$.

\subsection{Gravimetric Method}

The specimens were washing double with distilled water then acetone and dry. Solutions of $1 \mathrm{M}$ of hydrochloric<smiles>NC[C@@H](O)c1ccc(O)c(O)c1</smiles>

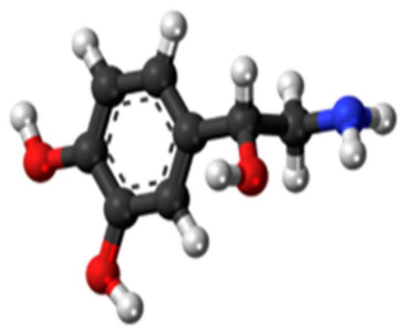

Figure 1. The chemical structure of the studied norepinephrine compound. 
acid were used as a blank solution. The inhibitor norepinephrine with concentrations $0.0,1 \times 10^{-3}, 2 \times 10^{-3}, 3 \times$ $10^{-3}, 4 \times 10^{-3}$ and $5 \times 10^{-3} \mathrm{mg} / \mathrm{ml}$, were added to the acid solution. Mild steel specimens were immersed in 250 $\mathrm{ml}$ of the various amounts of inhibitors for 6 hours of immersion each specimen in range of temperatures $30^{\circ} \mathrm{C}$, $40^{\circ} \mathrm{C}, 50^{\circ} \mathrm{C}$ and $60^{\circ} \mathrm{C}$. The mass of the specimens before and after immersion was determined using an analytical balance of $0.001 \mathrm{mg}$ accuracy. Averages of the duplicate values were used. After that the specimens were taken out, washed in a solution of $\mathrm{NaOH}$ and zinc dust, allowed to air dry and weighted accurately. Inhibition efficiencies (IE\%) and corrosion rates (CR) were calculated by using of the Equations (1) and (2):

$$
\begin{gathered}
\mathrm{IE} \%=\left(\frac{W_{2}-W_{1}}{W_{2}}\right) \times 100 \\
\mathrm{CR}=\frac{w}{A t}
\end{gathered}
$$

where $W_{1}$ and $W_{2}$ are the weight loss value in the presence and absence of inhibitor in $\mathrm{HCl}$ solution, respectively, $w$ is the corrosion weight loss, $A$ is the area of the mild steel specimen, $t$ is the immersion time. The surface coverage $\theta$ and IE\% is the inhibition efficiency was calculated according to Equations (3) and (4).

$$
\begin{gathered}
\theta=\left(\frac{C R_{2}-C R_{1}}{C R_{2}}\right) \times 100 \\
\mathrm{IE} \%=\theta \times 100
\end{gathered}
$$

\subsection{Morphology}

The surface morphology of the mild steel specimen was evaluated by scanning electron microscope (SEM) analysis. The specimen was immersed in $1 \mathrm{M}$ hydrochloric acid solution with and without $5 \times 10^{-3} \mathrm{mg} / \mathrm{ml}$, of the inhibitor. The specimen that shows high inhibition was examined with specimens without inhibitors and fresh steel.

\section{Results and Discussion}

Organic inhibitors represent cathodic and or anodic and play through a process of adsorption and formation of coating-film. Offer of molecules, display a strong affinity for metal surfaces and that will lead to formation a coordination compound with privilege of useful inhibition activity and reducing risky [30]. Inhibitors provide a barrier of protective hydrophobic film that adsorbs inhibitor molecules on the mild steel surface.

\subsection{Weight Loss Technique}

Corrosion inhibitor norepinephrine at various concentrations and temperatures were represented by Figure 2, in $1 \mathrm{~N}$ of hydrochloric acid with and without of norepinephrine. The corrosion rate (CR) in hydrochloric acid without of the norepinephrine was starting from 10 at $30^{\circ} \mathrm{C}$ and raised to 70 at $60^{\circ} \mathrm{C}$ as increasing sharply (see in Figure 2). Increasing of norepinephrine concentration lead to reducing the corrosion rate sharply at deferent temperatures.

IE\% increase with increasing of norepinephrine concntration. The effect of temperature on IE\% as shown from Figure 3 that the IE\% decrease with increasing of temperature and the maximum IE\% was at the maximum concentration $5 \times 10^{-3} \mathrm{mg} / \mathrm{mL}$ and the lowest temperature value at $30^{\circ} \mathrm{C}$. The increasing of IE\% with raise of norepinephrine is due to an increase in adsorption of the inhibitor at the higher concentration or increasing of the complexity between the metal surface and the corrosion inhibitor molecules via coordination bonds. At highest experimental temperature $50^{\circ} \mathrm{C}$ the IE\% was the lowest and this may be due to the denaturation of norepinephrine molecules with rising of temperatures.

\subsection{Mechanism of Inhibition}

The results obtained from weight loss measurements showed that norepinephrine inhibits the corrosion of mild steel in acidic media. This is due to the adsorption at the mild steel solution interface through film formation. It is a general assumption that the adsorption of norepinephrine at the metal surface interface is the first step in the 


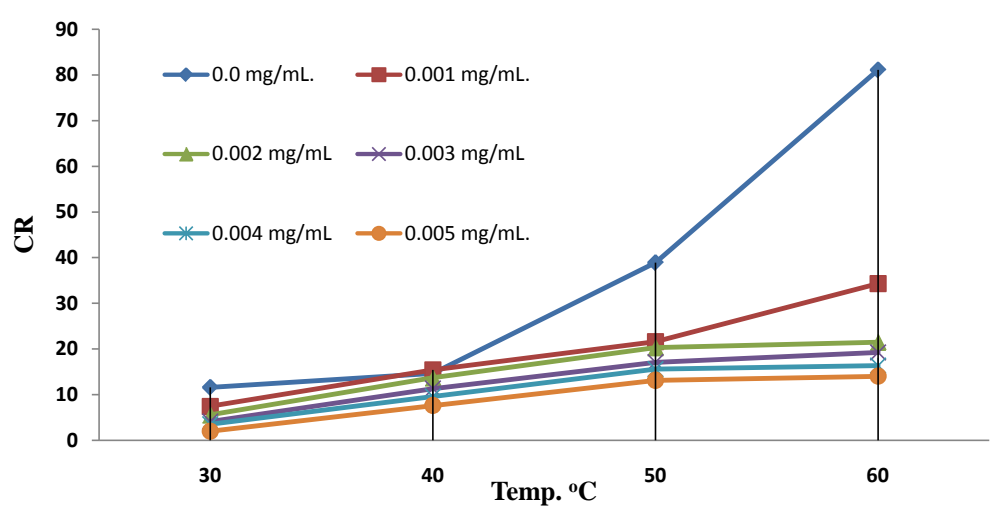

Figure 2. The corrosion rate for the mild steel corrosion at different temperature $1 \mathrm{~N} \mathrm{HCl}$ for various concentrations of inhibitor.

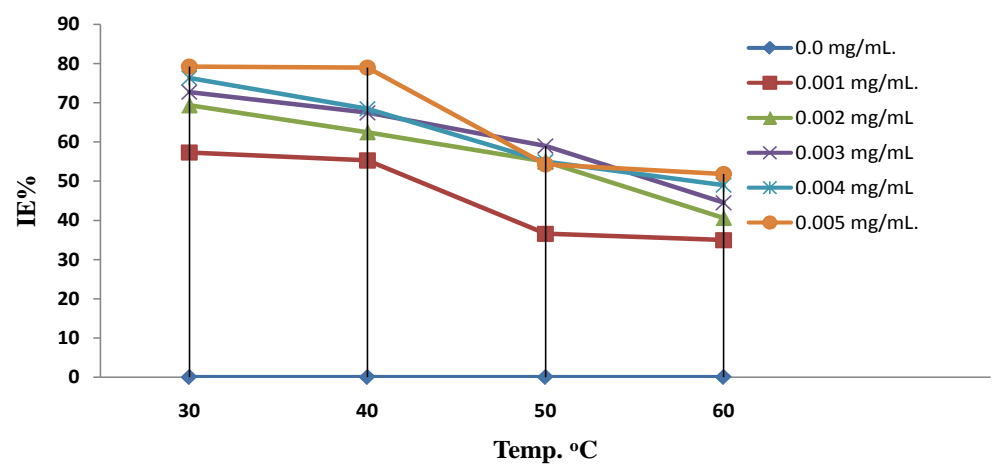

Figure 3. The inhibition efficiency for the mild steel corrosion at different temperature $1 \mathrm{~N} \mathrm{HCl}$ for various concentrations of inhibitor.

mechanism of the inhibitor action. The inhibitor may adsorb on the metal/acid solution interface by one or more of types, namely:

a) Electrostatic interaction between the charged molecules and the charged metal.

b) Donor-acceptor interactions between the p-electrons of aromatic ring and vacant $\mathrm{d}$ orbital of surface iron atoms.

c) Interaction of unshared electron pairs in the molecule with vacant $d$ orbital of iron surface atoms.

d) A combination of types a)-c).

It is often not possible to assign a single general mechanism of action to an inhibitor, because the mechanism may change with experimental conditions. Thus, the predominant mechanism of action of an inhibitor in acidic solutions may vary with factors such as concentration of the extracts, the nature of the anion of the acid, the presence of other species in the solution, the extent of reaction to form secondary inhibitors and the nature of the metal [31]. In this investigation two modes of adsorption could be considered, the neutral norepinephrine may adsorb onto the metal surface via the chemisorption mechanism, involving the displacement of water molecules from the metal surface and sharing electrons between the $\mathrm{O}$ and $\mathrm{N}$ atoms and Fe. The norepinephrine molecules can also adsorb on the metal surface on the basis of donor-acceptor interactions between $\pi$-electrons of aromatic ring and vacant d-orbitals of Fe. It is well known that iron has coordinate affinity toward nitrogen, and oxygenbearing ligand; hence, adsorption on iron can be attributed to coordination through the -NH group. These complexes might be adsorbed onto steel surface by vander Waals force to form a protective film to prevent mild steel from corrosion.

\subsection{Adsorption Isotherm}

Adsorption of the organic compound depends upon the charge and the nature of the metal surface, electronic characteristics of the metal surface on adsorption of solvent and other ionic species, temperature of the corrosion 
reaction and the electrochemical potential at the metal solution interface [32]. Adsorption of the norepinephrine involves two types of the possible interaction with the metal surface. The first one is weak undirected interaction due to electrostatic attraction between inhibiting organic ions or dipoles and the electrically charged surface of the metal. This interaction is termed physical adsorption or physisorption. The second type of interaction occurs when there is interaction between the adsorbate and adsorbent. This type of interaction involves charge sharing or charge transfer from adsorbate to the atoms of the metal surface in order to form a coordinate type bond and the interaction is termed chemical adsorption or chemisorptions [33]. It describes the adsorptive behavior of organic inhibitors to know the adsorption mechanism [34]. It depends mainly on the nature and charge of the metal surface, adsorption of solvent and other ionic species, electronic characteristics of the metal surface, temperature of the corrosion reaction at solution interface. The Langmuir isotherm was showed according to the adsorption isotherm of the corrosion rate (CR) data. Adsorption isotherm equilibrium constant is a very good indicator for the mechanism of inhibition, so if the value of adsorption isotherm equilibrium constant is high that mean strongly adsorbed on the metal surface.

$$
\theta=\frac{K C}{K C+1}
$$

where $K$ is the adsorption isotherm equilibrium constant and $C$ is concentration of the inhibitor.

$$
\begin{gathered}
\theta(K C+1)=K C \\
K+\frac{1}{C}=\frac{K}{\theta} \\
C+\frac{1}{K}=\frac{C}{\theta}
\end{gathered}
$$

To indicate that the adsorption mechanism was according to the Langmuir adsorption isotherm for different temperatures in hydrochloric acid we plot Figure 4, that represent the $C / \theta$ vs. $C$. Straight line indicating that norepinephrine was adsorbed according to the Langmuir adsorption isotherm.

The Langmuir isotherm, which is presented in Equation (8) is most often used to calculate the equilibrium constant [35] [36]. According to the Langmuir isotherm, $K_{\text {ads }}$ values can be calculated from the intercepts of the straight line of plotting $C / \theta$ versus $C$ (see Figure 4). The parameters of Langmuir isotherm are presented in Table 1 . The $R^{2}$ values of $0.9562,0.9682,0.9576$ and 0.9666 indicate strong adherence to Langmuir adsorption isotherm [37].

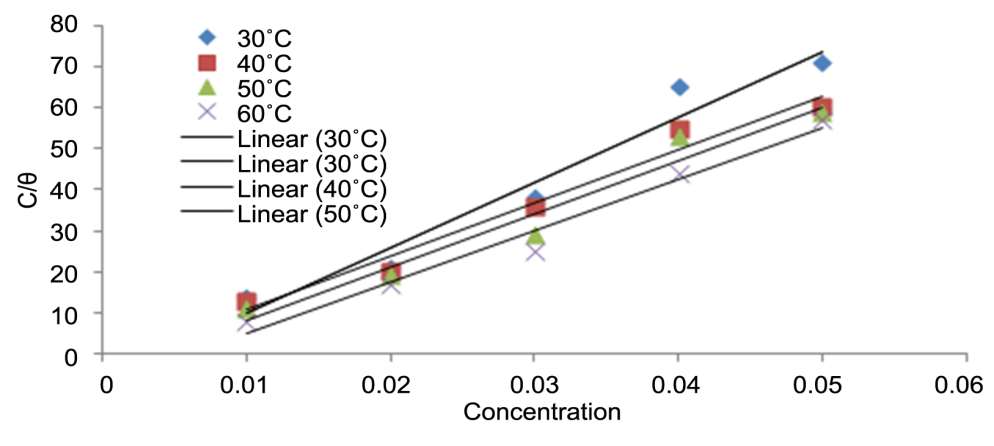

Figure 4. Langmuir plots for the corrosion inhibitor.

Table 1. Langmuir adsorption parameters for the inhibition of the corrosion of mild steel by norepinephrine.

\begin{tabular}{cccc}
\hline $\boldsymbol{T}(\mathbf{K})$ & $\mathbf{1} / \mathbf{K}$ & $\boldsymbol{K}(\mathbf{L} / \mathbf{m o l})$ & $\boldsymbol{R}^{\mathbf{2}}$ \\
303 & $444 \times 10^{-8}$ & 225419 & 0.9562 \\
313 & $624 \times 10^{-8}$ & 160270 & 0.9682 \\
323 & $797 \times 10^{-8}$ & 125520 & 0.9576 \\
333 & $1167 \times 10^{-8}$ & 85709 & 0.9666 \\
\hline
\end{tabular}




\subsection{Thermodynamic Characterisation}

There are ways that can enable us to get more information regarding the interaction of the studied inhibitor and metal surface at different temperatures. A good method is to use the thermodynamic model which can clarify the adsorption phenomenon of the inhibitor molecule. $\Delta H_{\text {ads }}$ may be determined from the Van't Hoff equation [38] [39]:

$$
\ln k_{a d s}=-\frac{\Delta H_{a d s}}{R T}+\text { Constant }
$$

where $\Delta H_{a d s}$ and $K_{a d s}$ are the adsorption heat and adsorptive equilibrium constant, respectively. The adsorptive equilibrium constant $\left(K_{\text {ads }}\right)$ is related to the standard free energy of adsorption $\left(\Delta G_{\text {ads }}\right)$ with the following Equation (10) [40]-[42]:

$$
\Delta G_{a d s}=-R T \ln K_{a d s}
$$

where $R$ is the gas constant and $T$ is the absolute temperature. Figure 5 is the straight line, a plot of $\ln K_{a d s}$ versus $1 / T$. The adsorption heat $\left(\Delta H_{a d s}\right)$ can be approximately regarded as the standard adsorption heat under the experimental conditions [39] [43]. Then the standard adsorption entropy $\Delta S_{a d s}$ can be obtained by the thermodynamic basic Equation (11):

$$
\Delta G_{a d s}=\Delta H_{a d s}-T \Delta S_{a d s}
$$

Figure 5 shows that $\Delta H_{a d s}=(-26.00 \mathrm{~kJ} / \mathrm{mol})$. Adsorption equilibrium constant $K_{a d s}$ and other thermodynamic parameters for the adsorption process are listed in Table 2.

A general analysis of the thermodynamic parameters shows that the complexation process is favored in terms of enthalpy $\left(\Delta H^{\circ}<0\right)$ but not in terms of entropy $\left(\Delta S^{\circ}<0\right)$ in all the above systems. Therefore, the complexation process is enthalpically controlled. The negative sign of $\Delta H_{\text {ads }}$ shows that the adsorption of norepinephrine molecules is an exothermic process. In an exothermic process, physisorption is distinguished from chemisorption by considering the absolute value of $\Delta H_{a d s}$. For physisorption process, the enthalpy of adsorption is lower than $40 \mathrm{~kJ} \cdot \mathrm{mol}^{-1}$ while that for chemisorptions approaches $100 \mathrm{~kJ} \cdot \mathrm{mol}^{-1}$ [44]. In this investigation, the standard adsorption heat $\left(-26.00 \mathrm{~kJ} \cdot \mathrm{mol}^{-1}\right)$ shows that a comprehensive adsorption (physical adsorption) might occur [38]. The adsorption of inhibitor molecules is accompanied by positive values of $\Delta S_{a d s}$.

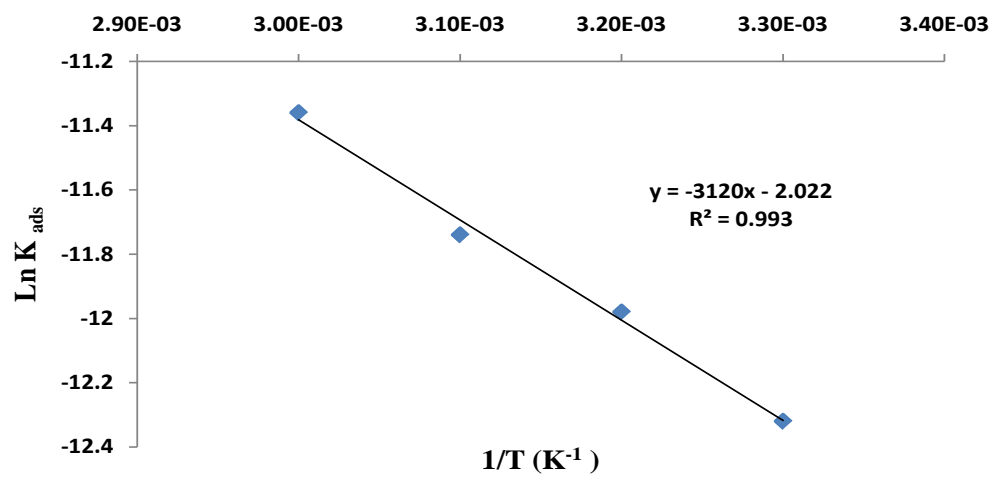

Figure 5. The relation between Ln $K_{a d s}$ and $1 / T$.

Table 2. Thermodynamic parameters for studied norepinephrine from experimental adsorption isotherm.

\begin{tabular}{ccccc}
\hline $\mathbf{T}(\mathbf{K})$ & $\mathbf{L n} \boldsymbol{K}_{\text {ads }}$ & $\Delta \boldsymbol{G}_{\text {ads }}(\mathbf{k J} / \mathbf{m o l})$ & $\Delta \boldsymbol{H}_{\text {ads }}(\mathbf{k J} / \mathbf{m o l})$ & $\Delta \boldsymbol{S}_{\text {ads }}\left(\mathbf{J} \cdot \mathbf{m o l}^{-\mathbf{1}} \cdot \mathbf{k}^{-\mathbf{1}}\right)$ \\
\hline 303 & 12.32 & -31.05 & -26.00 & 16.00 \\
313 & -11.98 & -31.19 & -26.00 & 16.50 \\
323 & -11.74 & -31.53 & -26.00 & 17.00 \\
333 & -11.36 & -31.45 & -26.00 & 16.36 \\
\hline
\end{tabular}


The negative value of $\Delta G_{a d s}$ means that the adsorption of norepinephrine molecules on steel surface is a spontaneous process, and furthermore the negative values of $\Delta G_{a d s}$ also show the strong interaction of the inhibitor molecule onto the mild steel [45].

Generally, values of $\Delta G_{a d s}$ around $\left(-20 \mathrm{~kJ} \cdot \mathrm{mol}^{-1}\right)$ or lower are consistent with the electrostatic interaction between the charged molecules and the charged metal (physisorption). If the results are more negative than -40 $\mathrm{kJ} \cdot \mathrm{mol}^{-1}$ it will involve charge sharing or transfer from the inhibitor molecules to the metal surface to form a coordinate type of bond (chemisorption) [16] [46]. In this investigation, the calculated values of $\Delta G_{a d s}$ are greater than $-40 \mathrm{~kJ} \cdot \mathrm{mol}^{-1}$, indicating that the adsorption of mechanism of norepinephrine molecules on steel in $1.0 \mathrm{M} \mathrm{HCl}$ solution at the studied temperatures may be a chemisorptions [47].

\subsection{Surface Morphology}

Figure 6 shows the corrosion surface of mild steel immersed in $1 \mathrm{M} \mathrm{HCl}$ with (Figure 6(b)) and without (Figure 6(a)) the inhibitor norepinephrine. Creating a rougher surface for the mild steel was done by aggressively acid. The difference was shown by Figure 6 in $\mathrm{HCl}$ with smoother surface due to the presences of norepinephrine. Mild steel in Figure 6 is due to the ability of prepared norepinephrine and an adsorbed film on the surface of mild steel that not found in Figure 6. The light damage a mechanism that leads to Figure 6 can explain under one of the following reasons; thin protective layer between the metal surface and anti-corrosion material through two ions. The chemical reaction between the inhibitor and the metal surface as the fact that the metal has d-orbitals and therefore bonds will be formed through the formation of coordination bonds between the metal and the inhibitor on the basis that the inhibitor is a ligand that containing nitrogen and oxygen-rich of electronic pairs as well as possession of double bonds and these electrons combine with the metal by transfer electrons from the ligand to the unoccupied d-orbitals of the metal and the formation of coordination bonds.

\section{Conclusion}

Norepinephrine acted as a good inhibitor for the corrosion of mild steel in $1 \mathrm{M} \mathrm{HCl}$ solution. Inhibition efficiency values increased with increase in inhibitor concentration but decreased with increase in temperature and had the highest inhibition efficiency of 79\%. The absorption of norepinephrine on mild steel in $1 \mathrm{M} \mathrm{HCl} \mathrm{solu-}$ tion obeys Langmuir isotherm. The value of $\Delta H_{\text {ads }}$ was negative, indicating that the sorption reaction was exothermic. The positive value of $\Delta S_{\text {ads }}$ shows the increasing randomness at the solid/liquid interface during the sorption of mild steel ions onto norepinephrine molecules. The negative value of $\Delta G_{a d s}$ confirmed the feasibility of the process and the spontaneous nature of sorption and chemically adsorbed (chemisorption) onto the steel surface with a high preference for mild steel to norepinephrine. Scanning Electron Microscopy (SEM) studies revealed that the corrosion of mild steel in $1 \mathrm{M} \mathrm{HCl}$ was reduced by the addition of the inhibitor. Smoother surfaces were observed to the treated mild steel with the inhibitor.

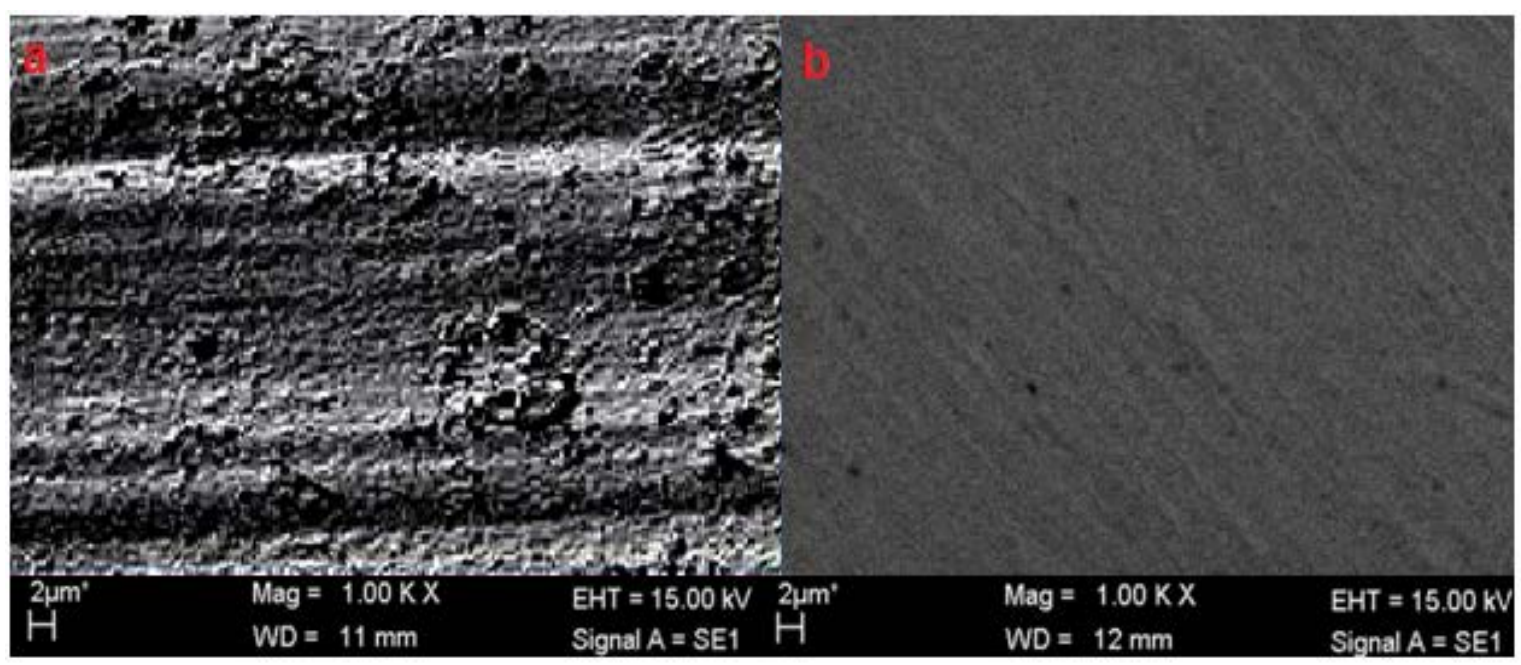

Figure 6. The scanning electron microscope micrographs 5000×. (a) Without inhibition; (b) With inhibition. 


\section{Acknowledgements}

The authors thank the Iraqi Government, Ministry of Higher Education and Basrah University for the financial support provided for this work.

\section{References}

[1] El-Dahan, H.A., Soror, T.Y. and El-Sherif, R.M. (2005) Studies on the Inhibition of Aluminum Dissolution by Hexamine-Halide Blends. Materials Chemistry and Physics, 89, 260-267.

http://dx.doi.org/10.1016/j.matchemphys.2004.07.024

[2] Antonijevic, M.M. and Petrovic, M.B. (2008) Copper Corrosion Inhibitors. A Review. International Journal of Electrochemical Science, 3, 1-28. http://www.electrochemsci.org/papers/vol3/3010001.pdf

[3] Fallavena, T., Antonow, M. and Goncalves, R.S. (2006) Caffeine as Non Toxic Corrosion Inhibitor for Copper in Aqueous Solutions of Potassium Nitrate. Applied Surface Science, 253, 566-571. http://dx.doi.org/10.1016/j.apsusc.2005.12.114

[4] Rajendran, S., Vaibhavi, S., Anthony, N. and Trivedi, D.C. (2003) Transport of Inhibitors and Corrosion Inhibition Efficiency. Corosion Science, 59, 529-534. http://dx.doi.org/10.5006/1.3277584

[5] El-Etre, A.Y. (2008) Inhibition of C-Steel Corrosion in Acidic Solution Using the Aqueous Extract of Zallouh Root. Materials Chemistry and Physics, 108, 278-282. http://dx.doi.org/10.1016/j.matchemphys.2007.09.037

[6] Christy, A.G., Lowe, A., Otieno-Alego, V., Stoll, M. and Webster, R.D. (2004) Voltammetric and Raman Microspectroscopic Studies on Artificial Copper Pits Grown in Simulated Potable Water. Journal of Applied Electrochemistry, 34, 225-233. http://dx.doi.org/10.1023/B:JACH.0000009923.35223.f8

[7] Otmacic, H., Telegdi, J., Papp, K. and Stupnisek-Lisac, E. (2004) Protective Properties of an Inhibitor Layer Formed on Copper in Neutral Chloride Solution. Journal of Applied Electrochemistry, 34, 545-550. http://dx.doi.org/10.1023/B:JACH.0000021873.30314.eb

[8] Ma, H., Chen, S., Niu, L., Zhao, S., Li, S. and Li, D. (2002) Inhibition of Copper Corrosion by Several Schiff Bases in Aerated Halide Solutions. Journal of Applied Electrochemistry, 32, 65-72. http://dx.doi.org/10.1023/A:1014242112512

[9] Zucchi, F., Trabanelli, G. and Fonsati, M. (1996) Tetrazole Derivatives as Corrosion Inhibitors for Copper in Chloride Solutions. Corrosion Science, 38, 2019-2029. http://dx.doi.org/10.1016/S0010-938X(96)00094-7

[10] Zucchi, F., Trabanelli, G. and Alagia, N. (1995) ACH-Models in Chemistry, 132, 579.

[11] Wang, C., Chen, S. and Zhao, S. (2004) Inhibition Effect of AC-Treated, Mixed Self-Assembled Film of Phenylthiourea and 1-Dodecanethiol on Copper Corrosion. Journal of Electrochemical Society, 151, B11-B15. http://dx.doi.org/10.1149/1.1627342

[12] Kendig, M. and Jeanjaquet, S. (2002) Cr(VI) and Ce(III) Inhibition of Oxygen Reduction on Copper. Journal of Electrochemical Society, 149, B47-B51. http://dx.doi.org/10.1149/1.1430717

[13] Ma, H.Y., Yang, C., Yin, B.S., Li, G.Y., Chen, S.H. and Luo, J.L. (2003) Electrochemical Characterization of Copper Surface Modified by $n$-Alkanethiols in Chloride-Containing Solutions. Applied Surface Science, 218, 144-154. http://dx.doi.org/10.1016/S0169-4332(03)00573-7

[14] Gomma, G.K. and Wahdan, M.H. (1994) Effect of Temperature on the Acidic Dissolution of Copper in the Presence of Amino Acids. Materials Chemistry and Physics, 39, 142-148. http://dx.doi.org/10.1016/0254-0584(94)90191-0

[15] Khaled, K.F. and Hackerman, N. (2004) Ortho-Substituted Anilines to Inhibit Copper Corrosion in Aerated 0.5 M Hydrochloric Acid. Electrochimica Acta, 49, 485-495. http://dx.doi.org/10.1016/j.electacta.2003.09.005

[16] Khamis, E., Bellucci, F., Latanision, R. and El Ashry, M. (1991) Acid Corrosion Inhibition of Nickel by 2-(Triphenosphoranylidene) Succinic Anhydride. Corrosion, 47, 677-686. http://dx.doi.org/10.5006/1.3585307

[17] El Ashry, E.S.H., El Nemr, A., Esawy, S.A. and Ragab, S. (2006) Corrosion Inhibitors: Part II: Quantum Chemical Studies on the Corrosion Inhibitions of Steel in Acidic Medium by Some Triazole, Oxadiazole and Thiadiazole Derivatives. Electrochimica Acta, 51, 3957-3968. http://dx.doi.org/10.1016/j.electacta.2005.11.010

[18] Growcock, F.B., Lopp, N.R. and Jasinski, R. (1988) Corrosion Protection of Oilfield Steel with 1-Phenyl-2-Propyn1-Ol. Journal of Electrochemical Society, 135, 823-827. http://dx.doi.org/10.1149/1.2095785

[19] Bouklah, M., Hammouti, B., Lagrenée, M. and Bentiss, F. (2006) Thermodynamic Properties of 2,5-bis(4-methoxyphenyl) -1,3,4-oxadiazole as a Corrosion Inhibitor for Mild Steel in Normal Sulfuric Acid Medium. Corrosion Science, 48, 2831-2842. http://dx.doi.org/10.1016/j.corsci.2005.08.019

[20] Wang, L., Yin, G.-J. and Yin, J.-G. (2001) 2-Mercaptothiazoline and Cetyl Pyridinium Chloride as Inhibitors for the Corrosion of a Low Carbon Steel in Phosphoric Acid. Corrosion Science, 43, 1197-1202. http://dx.doi.org/10.1016/S0010-938X(00)00138-4 
[21] Rani, B.E.A. and Bas, B.B.J. (2011) Green Inhibitors for Corrosion Protection of Metals and Alloys: An Overview. International Journal of Corrosion, 2012, 1-15. http://dx.doi.org/10.1155/2012/380217

[22] Fouda, A.S., Elewady, G.Y., Shalabi, K. and Habbouba, S. (2014) Gibberellic Acid as Green Corrosion Inhibitor for Carbon Steel in Hydrochloric Acid Solutions. Journal of Materials and Environmental Science, 5, 767-778. http://www.jmaterenvironsci.com/Document/vol5/vol5_N3/96-JMES-730-2014-Fouda.pdf

[23] Arthur, D.E., Jonathan, A., Ameh, P.O. and Anya, C. (2013) A Review on the Assessment of Polymeric Materials Used as Corrosion Inhibitor of Metals and Alloys. International Journal of Industrial Chemistry, 4, 1-9.

http://www.industchem.com/content/4/1/2 http://dx.doi.org/10.1186/2228-5547-4-2

[24] Umoren, S.A., Eduok, U.M. and Oguzie, E.E. (2008) Corrosion Inhibition of Mild Steel in $1 \mathrm{M} \mathrm{H}_{2} \mathrm{SO}_{4}$ by Polyvinyl Pyrrolidone and Synergistic Iodide Additives. Portugaliae Electrochimica Acta, 26, 533-546. http://www.peacta.org/articles upload/pea266533.pdf http://dx.doi.org/10.4152/pea.200806533

[25] Mathiyamsu, J., Nebru, I.C., Subramania, P., Palaniswamy, N. and Rengaswamy, N.S. (2001) Synergistic Interaction of Indium and Gallium in the Activation of Aluminium Alloy in Aqueous Chloride Solution. Anticorrosion Methods and Materials, 48, 324-329. http://www.emeraldinsight.com/doi/pdfplus/10.1108/EUM0000000005884 http://dx.doi.org/10.1108/EUM0000000005884

[26] Obot, I.B., Obi-Egbedi, N.O., Umoren, S.A. and Ebenso, E.E. (2010) Synergistic and Antagonistic Effects of Anions and Ipomoea invulcrata as Green Corrosion Inhibitor for Aluminium Dissolution in Acidic Medium. International Journal of Electrochemical Science, 5, 994-1007. http://www.electrochemsci.org/papers/vol5/5070994.pdf

[27] Obi-Egbedi, N.O., Obot, I.B. and Umoren, S.A. (2012) Spondias mombin L. as a Green Corrosion Inhibitor for Aluminium in Sulphuric Acid: Correlation between Inhibitive Effect and Electronic Properties of Extracts Major Constituents Using Density Functional Theory. Arabian Journal of Chemistry, 5, 361-373. http://dx.doi.org/10.1016/j.arabjc.2010.09.002

[28] Khalifa, O.R. and Abdallah, S.M. (2011) Corrosion Inhibition of Some Organic Compounds on Low Carbon Steel in Hydrochloric Acid Solution. Portugaliae Electrochimica Acta, 29, 47-56. http://dx.doi.org/10.4152/pea.201101047

[29] Evans, U.R. (1976) The Corrosion and Oxidation of Metals. Hodder Arnold, London.

[30] Yaro, A.S., Khadom, A.A. and Wael, R.K. (2013) Apricot Juice as Green Corrosion Inhibitor of Mild Steel in Phosphoric Acid. Alexandria Engineering Journal, 52, 129-135. http://dx.doi.org/10.1016/j.aej.2012.11.001

[31] Shreir, L.L., Jarman, R.A. and Burstein, G.T. (1994) Corrosion Metal Environment Reaction. Butterworth-Heinemann, London, 4-160.

[32] Villamil, R.F.V., Corio, P., Agostinho, S.M.L. and Rubim, J.C. (1999) Effect of Sodium Dodecylsulfate on Copper Corrosion in Sulfuric Acid Media in the Absence and Presence of Benzotriazole. Journal of Electroanalytical Chemistry, 472, 112-119. http://dx.doi.org/10.1016/S0022-0728(99)00267-3

[33] Trabanelli, G. (2006) Corrosion Inhibitors. In: Mansfeld, F., Ed., Corrosion Mechanism, Mercel Dekker, New York.

[34] Hmamou, D.B., Salghi, R., Zarrouk, A., Messali, M., Zarrok, H., Errami, M., Hammouti, B., Bazzi, L. and Chakir, A. (2012) Inhibition of Steel Corrosion in Hydrochloric Acid Solution by Chamomile Extract. Der Pharma Chemica, 4, 1496-1505. http://derpharmachemica.com/vol4-iss4/DPC-2012-4-4-1496-1505.pdf

[35] Bilgic, S. and Caliskan, N. (2001) An Investigation of Some Schiff Bases as Corrosion Inhibitors for Austenite Chromium-Nickel Steel in $\mathrm{H}_{2} \mathrm{SO}_{4}$. Journal of Applied Electrochemistry, 31, 79-83. http://dx.doi.org/10.1023/A:1004182329826

[36] Shockry, H., Yuasa, M., Sekine, I., Issa, R.M., Elbaradie, H.Y. and Gomma, G.K. (1998) Corrosion Inhibition of Mild Steel by Schiff Base Compounds in Various Aqueous Solutions: Part I. Corrosion Science, 40, 2173-2186. http://dx.doi.org/10.1016/S0010-938X(98)00102-4

[37] Acharya, S. and Upadhyay, S.N. (2004) The Inhibition of Corrosion of Mild Steel by Some Flouroquinolones in Sodium Chloride Solution. Transactions of the Indian Institute of Metals, 57, 297-306.

[38] Tang, L.B., Mu, G.N. and Liu, G.H. (2003)The Effect of Neutral Red on the Corrosion Inhibition of Cold Rolled Steel in 1.0 M Hydrochloric Acid. Corrosion Science, 45, 2251-2262. http://dx.doi.org/10.1016/S0010-938X(03)00046-5

[39] Zhao, T.P. and Mu, G.N. (1999) The Adsorption and Corrosion Inhibition of Anion Surfactants on Aluminium Surface in Hydrochloric Acid. Corrosion Science, 41, 1937-1944. http://dx.doi.org/10.1016/S0010-938X(99)00029-3

[40] Rajendran, S., Joanyb, R.M., Apparao, B.V. and Palaniswamyd, N. (2000) Synergistic Effect of Calcium Gluconate and $\mathrm{Zn}^{2+}$ on the Inhibition of Corrosion of Mild Steel in Neutral Aqueous Environment. Transaction of the SAEST, 35, 113-117. http://krc.cecri.res.in/ro_2000/121-2000.pdf

[41] Oguzie, E.E. (2005) Inhibition of Acid Corrosion of Mild Steel by Telfaria occidentalis Extract. Pigment and Resin 
Technology, 34, 321-326. http://dx.doi.org/10.1108/03699420510630336

[42] Arab, S.T. and Turkustuni, A.M. (2006) Corrosion Inhibition of Steel in Phosphoric Acid by Phenacyldimethyl Sulfonium Bromide and Some of Its p-Substituted Derivatives. Portugaliae Electrochimica Acta, 24, 53-69.

http://www.peacta.org/articles_upload/pea266533.pdf http://dx.doi.org/10.4152/pea.200601053

[43] Mu, G.N., Li, X.M. and Li, F. (2004) Synergistic Inhibition between o-Phenanthroline and Chloride Ion on Cold Rolled Steel Corrosion in Phosphoric Acid. Materials Chemistry and Physics, 86, 59-68. http://dx.doi.org/10.1016/j.matchemphys.2004.01.041

[44] Badiea, A.M. and Mohana, K.N. (2009) Effect of Temperature and Fluid Velocity on Corrosion Mechanism of Low Carbon Steel in Presence of 2-Hydrazino-4,7-dimethylbenzothiazole in Industrial Water Medium. Corrosion Science, 51, 2231-2241. http://dx.doi.org/10.1016/j.corsci.2009.06.011

[45] Elachouri, M., Hajji, M.S., Salem, M., Kertit, S., Aride, J., Coudert, R. and Essassi, E. (1996) Some Nonionic Surfactants as Inhibitors of the Corrosion of Iron in Acid Chloride Solutions. Corrosion, 52, 103-108. http://dx.doi.org/10.5006/1.3292100

[46] Donahue, F.M. and Nobe, K. (1965) Theory of Organic Corrosion Inhibitors: Adsorption and Linear Free Energy Relationships. Journal of Electrochemical Society, 112, 886-891. http://dx.doi.org/10.1149/1.2423723

[47] Al Hamzi, A.H., Zarrok, H., Zarrouk, A., Salghi, R., Hammouti, B., Al-Deyab, S.S., Bouachrine, M., Amine, A. and Guenoun, F. (2013) The Role of Acridin-9(10H)-One in the Inhibition of Carbon Steel Corrosion: Thermodynamic, Electrochemical and DFT Studies. International Journal of Electrochemical Science, 8, 2586-2605. http://www.electrochemsci.org/papers/vol8/80202586.pdf 